DOI 10.37882/2223-2982.2021.03-2.02

\title{
ПРОВЕДЕНИЕ КОНКУРСА ТВОРЧЕСКИХ ПРЕЗЕНТАЦИЙ С ИСПОЛЬЗОВАНИЕМ ИКТ
}

\section{CONDUCTING A COMPETITION OF CREATIVE PRESENTATIONS USING ITC N. Achkasova}

Summary: Analyzed in the article is the experience of conducting a creative presentations' contest with the help of information and communications technologies. Paying tribute to the new technologies of communication and to the advantages due to them in the conducting of collective events, the conclusion is made that online mode allows to have an interesting collective event, corresponding to all didactic principles. This virtual event combined the features of a training session, an interactive forum and a video meeting, which is a powerful resource in the modern world.

Keywords: information and communications technologies, digitalization, presentations' contest, didactic principles, motivation.

\author{
Ачкасова Наталья Николаевна \\ Доцент, Финансовый университет \\ при Правительстве РФ, (Москва) \\ Natalya.a4kasova@yandex.ru
}

Аннотация: В статье анализируется опыт проведения творческого конкурса презентаций с использованием ИКТ. Отдавая должное современным информационно-коммуникативным технологиям, и открывающейся возможности проведения коллективных мероприятий, делается вывод, что онлайн формат позволяет провести интересное коллективное мероприятие, соответствующее всем дидактическим принципам обучения. Данное мероприятие, проведенное виртуально, объединило в себе черты учебного занятия, интерактивного форума и видео встречи, что является могущественным средством образования в современном мире.

Ключевые слова: информационно-коммуникативные технологии, цифровизация, конкурс презентаций, дидактические принципы, мотивация.

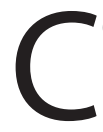
овременный мир стремительно меняется в сторону информатизации. Формирование и развитие информационного общества предлагает широкое применение информационно-коммуникативных технологий (ИКТ) в жизнедеятельности человека. Наука быстрыми шагами идет вперед, разрабатывая все более мощные цифровые технологии, поэтому встает вопрос осознанно подойти ко всему, что происходит в мире. «Цифровизация стала важнейшим критерием вовлеченности отдельной страны или людей в жизнь человечества. Тот, кто не имеет доступа к Глобальной сети, практически не существует в современном мире: он может заниматься чем угодно, но не будет при этом являться участником общего дела», считает Татьяна Черниговская $[2]$.

Действительно, развитие ИКТ вошло в жизнь каждого человека и коснулось такой основательной системы как образование, что определяется рядом факторов: внедрение ИКТ ускоряет передачу знаний и накопленного опыта; современные ИКТ позволяют человеку успешнее адаптироваться к окружающему современному цифровому миру; внедрение технологий в образование является фактором реформирования системы образования в свете требований новой «цифровой экономики». В условиях самоизоляции ИКТ позволили остаться на связи многим людям и продолжить свою деятельность.

Использование ИКТ уже далеко не ограничивается отбором и систематизацией нужной информации. Сегодня специалистов волнуют вопросы, связанные с поиском способов усвоения знаний в процессе практической деятельности. Ведь если техническая сторона на сегодняшний день решается в плановом режиме, то контентная составляющая цифрового образования оказалась слабее в силу организационных и методологических факторов. Тем не менее, ученые и методисты отмечают высокие коммуникативные возможности ИКТ. «Благодаря их использованию в обучении иностранным языкам, можно включить учащихся в активную учебную деятельность, что способствует развитию у них коммуникативных и навыков. Одним из приоритетных направлений использования средств ИКТ в процессе преподавания иностранных языков в вузе является реализация дидактических их возможностей, а именно осуществить автоматизированный контроль и самоконтроль результатов обучения, компьютерную визуализацию учебной иноязычной информации путем наглядного представления лексического, грамматического и фонетического материала, незамедлительную обратную связь между обучаемыми и средством обучения при интерактивном диалоге» [1]. Учителя и преподаватели разрабатывают методологию виртуальных занятий и мероприятий, способствующих хорошему освоению знаний и закреплению навыков по своим предметам.

Таким мероприятием стал творческий конкурс творческих бизнес презентаций, проходящий онлайн для студентов 1-2 курсов финансово-экономического факультета. Продолжался он 2 часа, однако ценность мероприятия трудно переоценить, так как все участники получили новый опыт, который необходимо проанали- 
зировать, что и представляется возможным в данной статье.

Как студенты восприняли свое участие в конкурсе презентаций? Что побудило их провести большую подготовительную работу и представить свой продукт, несмотря на неблагоприятные условия - конец семестра, надвигающаяся сессия, для многих непривычный формат онлайн участия. Что побуждало их искать материал на английском языке, анализировать, разрабатывать задания по теме, чтобы подготовить интересный продукт для презентации и подготовиться к хорошему выступлению? Вопросов возникает много и, вероятно, ответы пока будут гипотетичными, поскольку серьезное исследование с анкетами и интервью будет проведено позже.

Является ли такая форма занятия обучением иностранному языку? Эффективна ли она? Попробуем остановиться и проанализировать мероприятие с позиции педагогики и дидактических принципов. Проблема обучения всегда широко обсуждалась и изучалась педагогической общественностью. Много публикаций пришлось на конец 20 века: Ю.К. Бабанский, Н.В. Бордовская, О.С. Гребенюк, В.А Сластенин и другие. Обучение рассматривается как процесс формирования знаний, умений, навыков, способностей, приобретения практического опыта, а также развития личных качеств. Следует остановиться на таких педагогических факторах процесса обучения, которые изучаются дидактикой. Педагогический терминологический словарь дает следующее определение: «Теория образования и обучения, отрасль педагогики. Вскрывает закономерности усвоения знаний, умений и навыков и формирования убеждений, определяет структуру содержания образования, совершенствует методы и организационные формы обучения, воспитывающее воздействие учебного процесса на учащихся» [3]. Дидактика - это часть педагогики, занимающаяся общими закономерностями любого обучения, независимо от конкретного примера. Посмотрим на важнейшие дидактические принципы и проверим, отвечало ли им наше дистанционное мероприятие. Принцип коллективной деятельности. Обучение - это всегда совместная деятельность студента и преподавателя. Совместная - это когда преподаватель и студенты идут к совместной цели, выполняя определенные действия, чтобы ее достичь. Задача преподавателя организовать такое сотрудничество, в котором учащийся может проявить и развить то, чем уже владеет, в чем откроются новые горизонты изучаемого материала и для него, и для преподавателя. Нельзя сказать, что в современном преподавании имеется много форм работы, которые носят коллективный характер, рассчитаны на активное участие группы, отделения или факультета. Тем не менее, конкурс презентаций носил коллективный характер. Подготовка к выступлению с презентацией проводилась в течение месяца, и студенты могли обсуждать материал как с одногруппниками, так и с преподавателем, вынося проблемные вопросы на обсуждения. Преподаватели давали задания на парное/ групповое прочтение статей по темам, что способствовало групповой работе в факультетской библиотеке, написанию обратной связи. Само представление презентации, ответы на вопросы жюри и участников требовало серьезной подготовки, умению отобрать самое важное, интересное и уметь ответить, поддержать общение по своей теме. В процессе подготовки присутствовал учебный компонент, и сила учебного воздействия отобранного материала определялась самими студентами. Финальное мероприятие, конкурс творческих презентаций, является коллективной формой обучения: возможность обменяться своими умениями, навыками и достижения в своей учебно-профессиональной деятельности, что несомненно способствует повышению мотивации к изучению иностранных языков и повышению своей профессиональной компетенции.

Второй принцип активности. Активность - это мера или величина проявляемой человеком деятельности, степень его вовлеченности в работу. Активность является главным показателем учащегося его сознательного отношения к учебному процессу. Чтобы обучение было эффективным, именно студент должен проявлять инициативу и творчески подходить к предмету или мероприятию, уметь самостоятельно работать на занятии и вне его. Данное мероприятие помогло обеспечить, организовать и направить активность учащихся. Перед студентами была поставлена цель - разработать продукт (или взять имеющийся на рынке) и выработать эффективные пути запуска его на рынке. Вторая возможность была изучить наиболее успешные примеры создания продукта и вывода его на рынок. Студент использует свои знания, умения, навыки, которые заставляют его работать. Здесь же заложен и принцип проблемности. Учащиеся решали задачу, как представить свой продукт в презентации на английском языке. Известно, что сама по себе проблема еще не обеспечивает активность студента. Необходима потребность решить эту проблему, то есть нужна мотивация. Принцип мотивации - один из важных в дидактике. «Мотивация - это система взаимосвязанных и взаимоподчиненных мотивов деятельности личности, сознательно определяющих линию ее поведения» [4]. Большой вклад в разработку проблемы мотивации в области обучения иностранным языкам внесли А.Н. Леонтьев, А.А. Леонтьев, И.С. Зимняя, Е.И. Пассов и другие. Общим является, что в основе мотивации лежит осознание индивидом полезности и необходимости своих действий или деятельности в целом, а также предвосхищение чувства удовлетворения, получаемого от самого процесса деятельности или достижения ее цели. Мотивация участия в проекте по ответам студентов - желание увидеть свой профессиональный продукт на иностранном языке и поделиться этим с аудиторией. Решение этой задачи требовало совершить много действий, 
которые соотносятся с профессиональными интересами студента, такими как: читать профессиональную литературу на родном и иностранном языке, анализировать профессиональные новинки, отбирать необходимый материал по теме, представлять материал в форме презентации, выступать с презентацией онлайн.

Большинство этих действий аутентично, то есть представляют деятельность, которая будет востребована в будущем, в будущей профессиональной жизни. Задача преподавателя - помогать студенту развиваться, расти, исследуя новые формы.

Трудность возникает в том, что не все студенты одинаковы. Что легко одному, другому трудно и наоборот. Задание, интересное одному, неинтересно другому. Эффективность конкурса творческих презентаций обеспечивалась тем, что каждый мог работать в своем режиме. Студенты с разным уровнем профессиональной подготовки и подготовки по английскому языку могли участвовать. Задание - творческое и поэтому оставляет за студентом право выбрать самому, о чем рассказывать. Так как тема объявляется заранее, то есть время проработать ее и самостоятельно, и на консультациях. Таким образом реализуется еще один принцип дидактики - индивидуальности.

Данное мероприятие готовилось поэтапно. Подготовительный этап состоял в объявлении мероприятия, рассылки необходимой информации, вовлечение студентов участвовать в нем. Выяснив, что тема мероприятия посвящена экономическим вопросам (вопросам их специальности) и предполагает творческий подход к ее раскрытию, многие студенты захотели сразу участвовать. Несомненно, возможность консультаций с преподавателем рассматривалась как плюс к работе.

Исполнительный этап предполагал работу с профес- сиональной литературой, ее анализ, прочтение статей на английском языке, просмотр видео в интернете, посвященных тематике мероприятия. Необходимо было подготовить презентацию на английском языке и отрепетировать ее. На этом этапе преподаватель отрабатывал выступление на английском языке со студентами, имеющими недостаточно высокий уровень языка. Это и есть прекрасная мотивация для более слабых студентов в языке. Необходимо было тонко поддерживать каждого, чтобы они удержали оптимистический настрой.

Презентационный этап - кульминация мероприятия. Это один из напряженных этапов мероприятия, так как многие впервые выступали на английском языке онлайн. Члены жюри оценивали выступления и задавали вопросы, далее подключались и другие участники. Волнение добавляла техническая сторона, необходимость вовремя загрузить презентацию, расслышать вопрос, говорить, чтобы было слышно. Тем не менее, когда все шло гладко, это добавляло ощущение успеха.

В конце мероприятия онлайн студенты сделали памятные фотография, что говорит об удовольствии, полученном за время мероприятия.

Заключительный этап предполагает подведение итогов и его оценку. Решение студентов написать статьи после выступления, посвященные разработанной теме, говорит о положительном влиянии мероприятия на дальнейшую работу и учение языка.

Таким образом, проведение конкурсов презентаций с использованием ИКТ - это средство образования молодого поколения, повышения их профессионального кругозора, отработка подготовки презентаций и публичных выступлений онлайн на английском языке. Все эти умения и навыки являются необходимыми в профессиональной жизни.

\section{ЛИТЕРАТУРА}

1. Агальцова Д.В. «Методические подходы к использованию средств информационных и коммуникативных технологий в процессе преподавания иностранных языков в вузе»// в книге «Вызовы системы образования в эпоху цифровой экономики: матрица возможностей» т.2, М.2020, с.6.

2. Ежова В.А. «Татьяна Черниговская: цифровизация и человечность» [Электронный ресурс], - URL:http://eawpress.ru

3. Педагогический терминологический словарь. [Электронный ресурс], - URL: dic.academic.ru

4. Словарь терминов по общей и социальной педагогике. [Электронный ресурс]_Вокабула.РФ

(c) Ачкасова Наталья Николаевна (Natalya.a4kasova@yandex.ru). 